\title{
Effect of Cognitive Demand on Prospective Memory in Individuals with Traumatic Brain Injury
}

\author{
Annick Maujean and David Shum \\ Griffith University, Australia \\ Rachel McQueen \\ Princess Alexandra Hospital, Australia
}

\begin{abstract}
$\mathrm{T}_{\mathrm{n} \operatorname{sen}}$ his study aimed to evaluate the influence of cognitive demand on prospectivememory in individuals with traumatic brain injury (TBI) using a dual-task paradigm. Fourteen individuals with severe TBI and 14 matched controls were required to undertake two tasks. A lexical-decision task was used as an ongoing task and had two levels of cognitive demand (viz., low and high). The event-based prospective-memory task involved performing a specific action whenever a target stimulus appeared during the ongoing task. The Letter-Number Sequencing Test, the Tower of London and the Controlled Oral Word Association Test were also administered to assess the relationship between prefrontal lobe functions and prospective memory. As hypothesised, participants in the TBI group performed more poorly than participants in the control group on the prospective-memory task in the high but not in the low demand condition. There were significant correlations between prospective-memory task performance and scores on the Letter-Number Sequencing Test and the Controlled Oral Word Association Test. These findings help to clarify the nature of prospective-memory impairment in individuals with TBI and support the involvement of prefrontal processes in prospective remembering.
\end{abstract}

Memory impairment is one of the most common symptoms following traumatic brain injury (TBI; Shum, Harris, \& O'Gorman, 2000; Shum, Sweeper, \& Murray, 1996). The effect of this type of injury is often long-term, debilitating and difficult to remediate (Glisky \& Glisky, 2002). Historically, research examining the effects of TBI on memory has focused on a type of memory called retrospective memory, or the ability to remember past events or recall previously learned information (Levin, 1991; Richardson, 2000). Examples of retrospective memory impairment include forgetting the details of a television program watched the day before, or the inability to remember items of a grocery-shopping list. In recent years, researchers have become interested in studying the effect of TBI on a second type of memory, termed prospective memory, or the ability to remember to perform intended action(s) in the future (Shum, Fleming, \& Neulinger, 2002). The roots of prospective memory research can be traced back to the literature on ageing, where researchers were the first to become interested in the construct and to develop theories about and assessment procedures for this type of memory (Brandimonte, Einstein, \& McDaniel, 1996; Ellis \& Kvashvili, 2000). Examples of prospective memory impairment include forgetting to pay a telephone bill, forgetting to keep a doctor's appointment and forgetting to buy groceries on the way home, despite being able to

An earlier version of this paper was presented at the 25th ASSBI conference in Port Macquarie.

Address for correspondence: Dr David Shum, School of Applied Psychology, Griffith University, Nathan, QLD 4111, Australia. Email: d.shum@griffith.edu.au 
remember what is to be done both before and after the event.

There are two main reasons for the recent interest in prospective memory in the TBI literature. First, given that prospective memory focuses on "doing things" and "in the future", understanding it has important implications for the rehabilitation of individuals with TBI (Shum et al., 2002). Rehabilitation of TBI is generally directed to assisting individuals to perform actions competently, independently, and on time (e.g., carrying out duties at work, completing and submitting assignments at school), and for this prospective memory is essential. Second, while retrospective memory is mediated mainly by the medial temporal and hippocampal areas of the brain, prospective memory is considered to rely on the prefrontal lobes (Glisky, 1996). Because the prefrontal area is a commonly damaged area after TBI (Richardson, 2000; Williamson, Scott, \& Adams, 1996), individuals with TBI can be expected to show prospective memory impairment.

In one of the earliest studies, Mateer, Sohlberg, and Crinean (1987) asked a sample of 178 participants with brain injury and 157 controls to complete a questionnaire that focused on the frequency of forgetting. They found that memory failures relating to prospective memory and attention (compared to failures of retrospective memory) were perceived as occurring most often for both groups and that the braininjured group reported more problems than the controls in these two areas. Using another selfreport questionnaire, Roche, Fleming, and Shum (2002) asked 33 individuals with TBI and their significant others about the frequency of prospective forgetting. Although participants in the TBI group did not report greater prospective forgetting than controls, reports from significant others indicated that members of the TBI group, compared with controls, were more likely to show forgetting of basic and instrumental activities of daily living.

Kinsella et al. (1996) compared the performance of 24 individuals with TBI and 24 matched controls on two prospective-memory tasks, as well as on other memory measures. The first prospective-memory task required participants to ask the experimenter for a questionnaire and to remember its purpose at the end of the session. The second task required participants to return an evaluation form by mail and to write the date in the top corner. Compared to controls, performance of the TBI group was significantly poorer on the first but not on the second task.

Shum, Valentine, and Cutmore (1999) adopted a dual-task experimental paradigm developed by
Einstein, McDaniel, Richardson, and Guynn (1995) to study the effects of TBI on three types of prospective memory, namely, time-, event- and activity-based. A time-based task requires the participant to perform an intended action at a specific time, an event-based task requires the action to be performed when an external event or cue appears, and an activity-based task requires the action to be performed at the end of an activity. Compared to a group of 12 matched controls, a group of 12 individuals with severe long-term TBI were found to be impaired on all three types of prospective memory.

Kinch and McDonald (2001) administered two novel, yet ecologically valid, measures of prospective memory to 13 patients with severe TBI and 13 matched controls. They found that, compared to the controls, the patients performed significantly more poorly on the time- and event-based prospective memory tasks. These researchers also identified significant relationships between performance on the prospective-memory tasks and tests of executive functions (viz., the Wisconsin Card Sorting Test [WCST] and the Controlled Oral Word Association Test [COWAT]).

Overall, results of studies conducted to date indicate that individuals with TBI do exhibit prospective memory impairment. None of these studies, however, has attempted to clarify the nature or underlying mechanism of prospective forgetting in these individuals. Doing so is important, because clarifying the nature of prospective forgetting in individuals with TBI should help to improve the management and treatment of this type of impairment. As mentioned earlier, damage to the prefrontal area of the brain has been linked to prospective memory impairment in individuals with TBI, and Kinch and McDonald (2001) have found significant relationships between prospective-memory task performance and tests of prefrontal lobe functions. Nevertheless, this hypothesis has not been directly tested in individuals with TBI. In the literature on ageing, deterioration in the prefrontal area has been proposed as one of the main reasons for poorer prospective memory performance in older than younger individuals (West, 1996). In particular, prospective memory lapses are explained in terms of a reduction in efficiency of executive functions (viz., planning, monitoring, allocation of resources) in older individuals.

A number of studies have been conducted to test this idea in older individuals. In one such study, Park, Hertzog, Kidder, Morrell, and Mayhorn (1997) compared the performances of younger and older individuals on time- and event-based prospective tasks while undertaking a concurrent 
working-memory task. They found that participants in the older group performed significantly more poorly than participants in the younger group on both time- and event-based tasks, with a larger effect for the time-based task. However, the performance of a second group of older participants on a similar event-based prospective memory task was found to be without error when the working-memory task was not included. Park et al. argued that the poorer performance of the older group on the event-based prospective-memory task was due to a reduced ability to perform both the prospective and working-memory tasks efficiently, or, put another way, to reduced cognitive resources.

A study by Kidder, Park, Hertzog, and Morrell (1997) used a similar dual-task paradigm to test this idea by directly manipulating the cognitive load of the ongoing task (viz., a working memory task) and the prospective-memory task. As expected, Kidder et al. found that participants in the older group performed significantly more poorly than participants in the younger group on the prospective memory task in the high but not in the low load condition. They argued that the older group, compared with the younger group, was less efficient in performing the two tasks in the high load condition because fewer cognitive resources were available for the older group to deal with the increased demand of the tasks. Taken together, these results support the idea that poorer prospective memory in older individuals is due to a reduction in efficiency in prefrontal lobe functions, particularly a reduction in cognitive resources.

To determine if prospective impairment in TBI can be explained by a similar reduction in prefrontal lobe function, the present study examined the effect of cognitive demand on prospective-memory performance in individuals with TBI. The experimental paradigm used by Kidder et al. (1997) was considered unsuitable for the present study because it was developed for people without brain injury. Instead, a lexicaldecision task was used as the ongoing task with an event-based prospective-memory task. Compared to the working-memory task used by Kidder et al., lexical-decision is not as difficult, and was judged more likely to maintain interest and cooperation in participants with TBI. A second aim of this study was to explore the relationships between prospective memory performance and prefrontal lobe functions using three commonly used tests, namely, the Tower of London (TOL), Controlled Oral Word Association Test (COWAT) and the Letter-Number Sequencing Test (LNST). These tests were chosen because they measure processes (viz., working memory, cognitive flexibility, and planning) that are considered to relate to prospective memory in general and the experimental task of this study in particular.

It was expected that individuals with TBI would perform significantly more poorly on an event-based prospective-memory task when the cognitive demand of the ongoing task was high. Furthermore, it was expected that the difference in performance on the prospective memory task between individuals with TBI and matched controls would be greater in the high demand than in the low demand condition. Finally, based on the results reported by Kinch and McDonald (2001) significant correlations were expected between prospective-memory performance and scores on the three prefrontal-lobe tests.

\section{Method}

\section{Participants}

Two groups of participants took part in the study. The first group comprised 14 individuals (10 males and 4 females) who sustained a severe TBI, with an average time since injury of 9.71 months ( $S D=7.50$ months, range $=1-24$ months $)$. All these individuals had a score on the Glasgow Coma Scale (GCS) (Teasdale \& Jennett, 1974) that ranged from 3 to 15 at the time of admission to hospital and on average had experienced post traumatic amnesia (PTA) for 4.93 weeks $(S D=$ 3.29 weeks, range $=1-14$ weeks). Nine of these individuals sustained closed head injury as a result of a motor vehicle accident, two sustained closed head injury from a fall, and the remaining three sustained blunt head injury. Further information pertaining to the participants in the TBI group can be found in Table 1 .

The second group comprised 14 controls who had no history of TBI or other neurological problems. The two groups were matched in age and gender. The average ages for the TBI and control groups were 32.86 years $(S D=10.42$ years, range $=$ $19-53$ years) and 30.21 years $(S D=8.97$ years, range $=18$ to 49 years ). The two groups were not significantly different in age, $t(26)=.72, p>.05$. The mean number of years of education for the TBI and control groups was 11.57 years $(S D=1.70$ years) and 12.14 years $(S D=1.29$ years $)$, respectively, and the groups were not significantly different on this variable, $t(26)=-1.00, p>.05$. Participants in the TBI group were recruited from the Commonwealth Rehabilitation Services in Brisbane and the Brain Injury Unit at the Princess Alexandra Hospital. The control participants were recruited from the general community in Brisbane. 
TABLE 1

Details of Participants in the TBI Group

\begin{tabular}{|c|c|c|c|c|c|c|c|}
\hline Gender & $\begin{array}{l}\text { Age at } \\
\text { Injury } \\
\text { (Years) }\end{array}$ & $\begin{array}{l}\text { Age at } \\
\text { Testing } \\
\text { (Years) }\end{array}$ & $\begin{array}{l}\text { Time Since } \\
\text { Injury } \\
\text { (Months) }\end{array}$ & $\begin{array}{l}\text { Nature of } \\
\text { Injury }\end{array}$ & PTA & $\begin{array}{l}\text { GCS } \\
\text { Score }\end{array}$ & MRI/CT Scan Findings \\
\hline Male & 21 & 23 & 24 & $\begin{array}{l}\text { Motor vehicle } \\
\text { accident }\end{array}$ & 3 weeks & 8 & $\begin{array}{l}\text { (L) frontal lobe } \\
\text { hemorrhage }\end{array}$ \\
\hline Male & 35 & 35 & 6 & Blunt head injury & 6 weeks & 8 & $\begin{array}{l}\text { Fractured maxillary } \\
\text { sinuses bilaterally; } \\
\text { fractured }(R) \\
\text { zygomatic arch; } \\
\text { fractured }(R) \text { frontal } \\
\text { bone }\end{array}$ \\
\hline Male & 21 & 23 & 17 & Blunt head injury & 1 week & n.a. & Frontal hemorrhage \\
\hline Male & 29 & 31 & 26 & $\begin{array}{l}\text { Motor vehicle } \\
\text { accident }\end{array}$ & 2 weeks & 7 & (L) forehead laceration \\
\hline Male & 21 & 21 & 6 & $\begin{array}{l}\text { Motor vehicle } \\
\text { accident }\end{array}$ & 4 weeks & 13 & $\begin{array}{l}\text { Frontal contracoup } \\
\text { injury }\end{array}$ \\
\hline Male & 29 & 29 & 5 & Fall & 6 weeks & 6 & $\begin{array}{l}\text { (L) parietal subdural } \\
\text { haemotoma; fractured } \\
\text { (R) parietal \& petrous } \\
\text { temporal bones }\end{array}$ \\
\hline Male & 53 & 53 & 4 & Fall & 5 days & 15 & $\begin{array}{l}\text { (L) temporal parietal } \\
\text { contusion \& }(R) \text { frontal } \\
\text { lobe contusions }\end{array}$ \\
\hline Male & 41 & 41 & 1 & $\begin{array}{l}\text { Motor vehicle } \\
\text { accident }\end{array}$ & 6 weeks & 10 & $\begin{array}{l}\text { (L) basal ganglia, } \\
\text { petechial hemorrhage }\end{array}$ \\
\hline Male & 48 & 48 & 8 & Blunt head injury & 5 weeks & 8 & $\begin{array}{l}\text { (L) frontal \& parietal } \\
\text { chronic subdural } \\
\text { haematoma }\end{array}$ \\
\hline Male & 19 & 19 & 6 & $\begin{array}{l}\text { Motor vehicle } \\
\text { accident }\end{array}$ & 14 weeks & 3 & $\begin{array}{l}\text { Bilateral frontal \& } \\
\text { temporal lobes \& (L) } \\
\text { parietal lobe } \\
\text { contusions }\end{array}$ \\
\hline Female & 41 & 42 & 9 & $\begin{array}{l}\text { Motor vehicle } \\
\text { accident }\end{array}$ & 5 weeks & 9 & $\begin{array}{l}\text { (L) temporal contusion } \\
\& \text { subdural } \\
\text { hemorrhage }\end{array}$ \\
\hline Female & 31 & 31 & 6 & $\begin{array}{l}\text { Motor vehicle } \\
\text { accident }\end{array}$ & 4 weeks & 5 & $\begin{array}{l}\text { Fractured base of skull } \\
\&(\mathrm{~L}) \text { temporal } \\
\text { contusion }\end{array}$ \\
\hline Female & 25 & 26 & 12 & $\begin{array}{l}\text { Motor vehicle } \\
\text { accident }\end{array}$ & 4 weeks & 6 & $\begin{array}{l}\text { (L) fractured base } \\
\text { of skull }\end{array}$ \\
\hline Female & 38 & 38 & 6 & $\begin{array}{l}\text { Motor vehicle } \\
\text { accident }\end{array}$ & 8 weeks & 8 & $\begin{array}{l}\text { Fractured }(\mathrm{L}) \text { petrous } \\
\text { and parietal bones; } \\
\text { (L) temporo-parietal } \\
\text { introcerebral } \\
\text { hemorrhage }\end{array}$ \\
\hline
\end{tabular}

Note: n.a. $=$ not available

All participants received a movie ticket for taking part in the study.

\section{Materials}

An IBM-compatible notebook computer equipped with a six-button response keypad (Cedrus Corporation) was used for presenting stimuli and recording performance for the experimental tasks of the study. To assess prefrontal lobe functions, three psychological tests were administered: the Tower of London (TOL), the COWAT and the Letter-Number Sequencing Test (LNST) from the third edition of the Wechsler Memory Scale (WMS-III). 
In this study, prospective memory was assessed using a dual-task paradigm. The two tasks were a lexical-decision task (the ongoing task) and an event-based prospective memory task. The Superlab Pro (Version 1.04) software package (Abboud \& Sugar, 1997) was used to program these tasks.

\section{Lexical-decision Task}

This task was used as the ongoing task and it had two conditions (viz., low and high cognitive demand). Participants were presented with a random series of four-letter stimuli at the centre of the computer screen. They were required to indicate whether the stimulus was a word or a non-word by pressing the first button (coloured green) for word and the second button (coloured red) for nonword on a six-button response keypad. The duration of the task was 25 mins and consisted of 196 four-letter stimuli in each condition. To enhance participants' understanding of the instructions and requirements of the task, a 5 -min practice trial was given before each of the 25-min trials.

In the low cognitive-demand condition, the four letters for each stimulus were presented simultaneously on the computer screen. In the high cognitive-demand condition the four letters were presented one at a time. In both conditions, the stimuli consisted of 30 words and 30 nonwords each presented three times, and eight prospective-memory target items and eight corresponding non-words each presented once only. The Kucera and Francis (1967) word frequency norms were used in generating the word lists. Words of moderate to high frequency, as defined by these norms, were selected and were randomly allocated to the low and high demand conditions. The non-word lists were generated by changing the last letter of the words (e.g., SNOW to SNOX). This procedure was adopted to ensure that participants viewed the entire word in the high demand condition before deciding whether the item presented was a word or a non-word. For example, an item such as "ZXYD" can be easily identified as a non-word after presentation of one or two letters, whereas an item such as "ONTI" requires the viewing of all four letters before a lexical decision can be made. To enhance clarity, the stimuli were presented on the computer screen in block letters using Arial font (size 60). To minimise visual discomfort, the letters appeared in yellow on a dark blue background.

In the low cognitive-demand condition, the four letters for each stimulus appeared simultaneously for $2.75 \mathrm{~s}$. In the high cognitive-demand condition, the four letters were presented one letter at a time. Each letter appeared on the screen for 0.50 $\mathrm{s}$, with a short pause of $0.25 \mathrm{~s}$ between letters (total duration for the whole word was $2.75 \mathrm{~s}$ ). In both the low and high working-memory demand conditions, a cue signal ("+") was presented for $0.50 \mathrm{~s}$ followed by a short pause of $0.25 \mathrm{~s}$ duration before each item. The inter-item interval was $2.50 \mathrm{~s}$. In both the low and high cognitive-demand conditions, the total time for the presentation of each item was, therefore, $6 \mathrm{~s}$.

\section{Event-based Prospective Memory Task}

The second component of the dual-task paradigm consisted of an event-based prospective-memory task. The task involved asking the participant to remember to perform an action whenever presented with a cue. The specific action was pressing the sixth key on the response keypad whenever a target stimulus (a four-letter animal word) was presented during the lexical-decision task. The first and the second keys were red and green in colour and the third to sixth keys were all grey. The eight target stimuli in each cognitivedemand condition appeared randomly during the 25 mins of the lexical-decision task. Examples of the target stimuli and their corresponding nonwords include "LAMB" "LAMD", "FROG" "FROC", and "WOLF" "WOLB".

\section{Tower of London (TOL)}

The TOL was used to assess the prefrontal lobe function of planning (Lezak, 1995). This study used a version of TOL developed by Tunstall (1999) who increased the number of wooden disks from three to four to overcome a ceiling effect commonly found in the original TOL (Levin et al., 1997). The four-disk TOL was found to have adequate psychometric properties and to be sensitive in detecting planning impairment in children and adults with TBI (Shum et al., 2000; Shum, Tunstall, O'Gorman, \& Maujean, 2003). In this test, an individual is presented with a standard array of four coloured disks (white, yellow, blue and black) on three pegs of varying lengths and asked to achieve a given arrangement in a stated number of moves by shifting the disks one at a time from one peg to another. The same initial position is set for each of the 10 graded problems (number of moves required ranged from 3 to 9) with three attempts allowed per problem. The measure obtained for this test is the percentage of problems correctly solved within the three attempts. 


\section{Controlled Oral Word Association Test (COWAT)}

This test was used to evaluate the prefrontal function of spontaneous flexibility (Spreen \& Strauss, 1998). In this test, an individual is asked to produce orally as many words as possible beginning with the letters F, A and S, with a $60 \mathrm{~s}$ time limit for each of the letters. Test-retest reliability has been reported as .88 for adults after a period of 19 to 42 days (desRosiers \& Kavanagh, 1987) and .70 for older adults after 1 year (Welsh, Groisser, \& Pennington, 1988). According to Pachana, Boone, and Miller (1996), the COWAT places significant demands on the executive abilities of individuals suffering from frontal lobe damage. The measure obtained for this test is the total of all admissible words produced for the three letters F, A, S. Inadmissible words such as proper nouns, repetitions, and variations are not included in the total.

\section{Letter-Number Sequencing Test (LNST)}

This is a test of working memory capacity. It involves the auditory presentation of lists of letters and numbers to an individual (e.g., F - 4 $\mathrm{B}-7$ ), who is then required to repeat the numbers first in ascending order, and then the letters in alphabetical order (e.g., 4-7-B - F). The test consists of seven items with three trials per item. The list length ranges from two to eight and the total score obtained ranges from 0 to 21 . The psychometric properties of this test are good (Wechsler, 1997) and it has been found that patients with frontal lobe damage are significantly impaired on the LNST (Wechsler, 1997).

\section{Design and Procedure}

The design of the study was a $2 \times 2$ mixed-factorial with a between-subjects variable of Group (TBI vs. control) and a within-subjects variable of Cognitive Demand (low vs. high). The dependent variable was the percentage of correct responses for the event-based prospective-memory task.

All participants were tested individually in one session lasting approximately 2 hours, in a laboratory at Griffith University or at a quiet location in the participant's home. All participants began the session with the experimental tasks. They were all administered the two conditions of low and high cognitive demand, counterbalanced to control for fatigue and order effects. All participants were offered the opportunity to have a 15 - to 20 -min break between the two conditions. The experimental tasks were described as a language task and participants were not informed during the study that it was concerned with memory.

Upon completion of the experimental tasks, a brief interview was conducted during which participants were asked to repeat the instructions for the two tasks. They were also presented with a list of 46 words including the 16 target stimuli (i.e., the animal words). They were required to identify all animal words presented within this list to ensure that they were able to recognise the target items. Participants were then administered the three prefrontal lobe tests (viz., TOL, COWAT and LNST).

\section{Results}

\section{Lexical-decision Task}

Although this task was used as a filler activity, the percentages of correct responses for the TBI and control groups in the low and high cognitivedemand conditions were compared (see Figure 1). The results of a $2 \times 2$ (Cognitive Demand $\times$ Group) mixed ANOVA indicated that the main effects for Cognitive Demand, $F(1,26)=38.097$, $p<.001$, and Group, $F(1,26)=10.028, p<.02$, were both significant. In addition, the two-way interaction was significant, $F(1,26)=12.324$, $p<.01$. However, the high percentages of correct responses for the two groups indicate that the lexical-decision task was a satisfactory means of engaging the participants.

During the post-task interview, participants were required to repeat the instructions for the two experimental tasks. All participants (TBI and controls) were able to repeat the instructions correctly. The participants were also required to identify the 16 target items (i.e., the animal words) which were included within a list of 46 words. On average, the TBI group successfully identified $95.64 \%(S D=3.83 \%)$ of the animal words, and the control group identified $98.71 \%$ ( $S D=$ $2.55 \%)$. There was a significant difference between the two groups, $t(26)=-2.49, p<.05$. However, the high percentage of correct responses across the two groups suggests that participants in both groups were able to recognise most of the target stimuli as animal words. As mentioned in the Method section, participants were not informed that the experimental tasks were memory related and only three of the 28 participants (two from the control group and one from the TBI group) reported that the study was to do with memory. The three participants, however, were not excluded from the study. This is because these three participants reported that they tried equally hard on the ongoing and the prospective-memory 


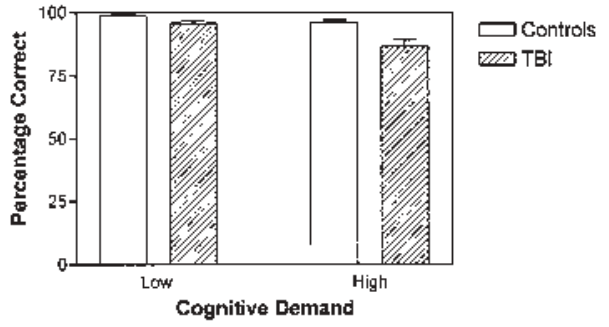

FIGURE 1

Mean percentage correct on the lexical-decision task for participants in the TBI and control groups.

tasks and that the results for the prospective memory task were found to be the same with and without these participants.

\section{Event-based Prospective-memory Task}

The mean percentages of correct responses for the prospective-memory task in the two cognitive-demand conditions for the two groups of participants are shown in Figure 2. These percentages were subjected to a $2 \times 2$ (Group $\times$ Cognitive Demand) mixed ANOVA. Results revealed a significant Cognitive Demand main effect, $F(1,27)=17.53, p<.01$, a significant Group main effect, $F(1,27)=7.10, p<.05$, and a significant Group by Cognitive Demand interaction, $F(1,27)=8.57, p<.05$.

To explore the source of the significant interaction, simple main effect analyses were conducted. Results revealed no significant difference between the performance of the TBI and control groups in the low cognitive-demand condition, $t(26)=-1.44, p>.05$, but there was a significant difference between the two groups in the high cognitive-demand condition, $t(26)=$ $-3.56, p<.01$. In addition, the results indicated that participants in the TBI group performed significantly better in the low than the high cognitive-demand condition, $t(13)=4.77, p<$ .01 , but the participants in the control group did not show a significant difference between the two conditions, $t(13)=.945, p>.05$.

\section{Prefrontal Lobe Measures}

The performances of the two groups of participants on the three prefrontal lobe tests are summarised in

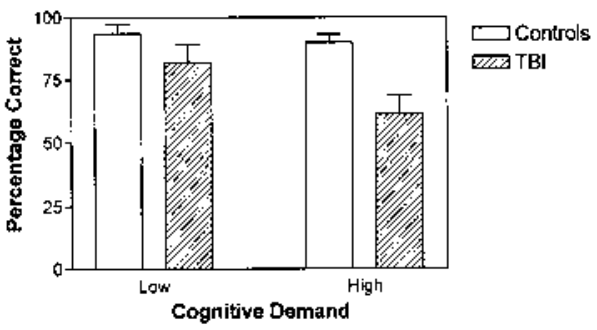

\section{FIGURE 2}

Mean percentage correct on the event-based prospective-memory task for participants in the TBI and control groups.

Table 2. As expected, participants in the TBI group performed significantly more poorly than participants in the control group on all three tests. The correlations between prospective-memory task performance and measures of the three prefrontal-lobe tests are summarised in Table 3. In the low and high cognitive-demand conditons, no significant correlations were found between the TOL and prospective-memory performance for either group. In the low cognitive-demand condition, there was a significant correlation between the the COWAT and prospectivememory task performance for the TBI but not the control group. In the low cognitive-demand condition, there was a significant correlation between the LNST and prospective-memory performance for the TBI as well as the control group but no significant correlations were found in the high cognitive-demand condition.

\section{Discussion}

The present study aimed to evaluate the effect of increased cognitive demand on prospectivememory performance in individuals with TBI. It was expected that (a) individuals with TBI would perform more poorly on an event-based prospective-memory task when the cognitive demand of the ongoing task was increased, and (b) the difference in prospective-memory task performance between the TBI and control groups would be greater in the high than the low cognitive-demand condition. Results obtained supported the hypotheses. While the performance of participants in the TBI group on the event-based prospectivememory task decreased significantly when the 


\section{TABLE 2}

Performance of the Two Groups on the Three Prefrontal Lobe Tests

\begin{tabular}{|c|c|c|c|c|c|}
\hline \multirow[b]{2}{*}{ Tests } & \multicolumn{2}{|c|}{ TBI } & \multicolumn{2}{|c|}{ Controls } & \multirow[b]{2}{*}{$t(26)$} \\
\hline & M & $S D$ & M & $S D$ & \\
\hline TOL (percentage correct) & 75.71 & 11.58 & 83.57 & 7.45 & $-2.14^{*}$ \\
\hline COWAT (number of words) & 31.93 & 8.22 & 46.36 & 8.51 & $-4.56^{* *}$ \\
\hline LNST (total score) & 10.21 & 2.72 & 14.64 & 2.68 & $-4.34^{* *}$ \\
\hline
\end{tabular}

Note: ${ }^{*} p<.05,{ }^{* *} p<.01$

\section{TABLE 3}

Correlations Between Prospective-memory Task Performance and Measures of Prefrontal Lobe Tests

\begin{tabular}{|c|c|c|c|c|}
\hline \multicolumn{5}{|c|}{ Performance on Event-based Prospective-memory Task } \\
\hline \multirow[b]{2}{*}{ Tests } & \multicolumn{2}{|c|}{$\mathrm{TBI}(N=14)$} & \multicolumn{2}{|c|}{ Controls $(N=14)$} \\
\hline & Low Demand & High Demand & Low Demand & High Demand \\
\hline $\mathrm{TOL}$ & .20 & .29 & .24 & .30 \\
\hline COWAT & .38 & $.72^{* *}$ & .22 & .23 \\
\hline LNST & $.54^{*}$ & .35 & $.52^{*}$ & -.12 \\
\hline
\end{tabular}

Note: ${ }^{*} p<.05,{ }^{* *} p<.01$

cognitive demand of the ongoing task was increased, the performance of participants in the control group did not. In addition, participants in the TBI group were found to perform significantly more poorly than participants in the control group on the prospective-memory task in the high but not the low cognitive-demand condition.

In general, these results are similar to those reported by Park et al. (1997) and Kidder et al. (1997) who examined the effect of increasing the cognitive load of an ongoing task on a secondary prospective-memory task in older individuals. Findings in the present study can be explained in terms of the commonly reported damage to the prefrontal area of the brain in individuals with TBI. The impaired performance of participants in the TBI group on the prospective-memory task in the high but not in the low cognitive-demand condition is likely to be due to a reduction in efficiency of prefrontal lobe functions or a reduction in cognitive resources. That is, when the cognitive demand of the ongoing task was low, participants in the TBI group were able to allocate resources adequately between the ongoing and the prospective-memory tasks. However, when the cognitive demand of the ongoing task was high, most of the resources available to participants in the TBI group were likely to have been taken up by the ongoing task, and, as a result, fewer cognitive resources were available for the prospective-memory task, leading to a decrease in the level of performance.
According to this explanation, the same reduction in performance for the prospective memory task did not occur for participants in the control group because they were able to distribute cognitive resources between the ongoing and prospective memory tasks in both the low and high cognitivedemand conditions.

The second aim of the present study was to explore the relationships between prospective memory and other prefrontal lobe functions such as working memory, spontaneous flexibility and planning. As expected, participants in the TBI group were found to perform significantly more poorly than participants in the control group on measures of all three tests of prefrontal lobe functions. Other researchers have reported the same finding (e.g., Shum et al., 2000; Wechsler, 1997). More interesting and important, however, was the finding of a number of significant correlations between performance on the event-based prospective-memory task and measures of the three prefrontal-lobe tests.

For participants in both the TBI and control groups, performance on the prospective-memory task was found to correlate significantly with the LNST in the low but not high cognitive-demand condition. The LNST is a test of working memory and measures the ability to actively maintain and process information in short-term storage (Wechsler, 1997). The significant relationship between prospective memory and working memory could be due to the fact that, for the dual-task experimental paradigm adopted for this study, an 
individual has to actively maintain or remember the requirements for the event-based prospective memory task (e.g., the nature and characteristics of the target stimulus, which button to press when the stimulus appears) while undertaking the ongoing task. This, however, should apply for both the low and high cognitive-demand conditions and does not explain why a significant correlation was only found in the low cognitive-demand condition. This unexpected finding could be due to the lack of power associated with the small sample size in this study. It could also be due to the fact that the processes required for successful performance on the prospective memory task changes when the cognitive demand increases.

A significant relationship was also found between performance on the event-based prospective-memory task and the COWAT in the high cognitive-demand condition for participants in the TBI group. The COWAT is a test of spontaneous flexibility and has been found to place significant demands on the executive abilities of individuals suffering from frontal lobe damage (Pachana et al., 1996; Spreen \& Strauss, 1998). This demand on the executive abilities could explain why performance on this test was found to correlate significantly with prospective-memory task performance on the high but not the low cognitive demand condition.

The only prefrontal lobe test that did not correlate significantly with performance on the event-based prospective-memory task was the TOL, a test that measures the ability to plan (Lezak, 1995). This could be because in this study only one prospective-memory task and one ongoing task were used and neither of these tasks is complex. As such, performance on these experimental tasks might not require much planning. The relationship between planning and prospective memory can be clarified in future studies by using more complex ongoing and prospectivememory tasks.

The findings of the present study have a number of implications. Unlike previous studies that showed that individuals with TBI are impaired in prospective memory, the present study was designed to clarify the nature and underlying mechanisms of prospective forgetting in these individuals. Results obtained suggest that prospective-memory impairment in individuals with TBI can be explained in terms of a reduction of cognitive resources in these individuals. By examining the relationships between prospectivememory task performance and scores on three prefrontal lobe tests, results obtained further suggest that working memory and spontaneous flexibility are important prefrontal lobe processes that are related to prospective memory. Together these two findings provide further evidence to support the contribution of prefrontal lobe functions in prospective memory and provide further justification for the study of prospective memory as a type of memory that is different from and independent of retrospective memory.

Practically, the findings of this study can provide suggestions for professionals who help individuals with TBI to deal with or manage prospective-memory impairment. To improve the prospective memory of these individuals, one needs to pay attention to the context in which they are required to carry out a delayed intention. If there are many ongoing activities between the encoding and retrieval of the intention and if the cognitive demand of these ongoing activities is high, it is important that strategies (e.g., reducing the cognitive load of the task, using internal and external aids, reminding them of the significance of successful remembering and the consequences of prospective forgetting) be developed to assist them in remembering when and where to carry out the delayed intention.

Findings of the present study, however, have a number of limitations. First, only 14 participants were included in the TBI group and this has the effect of limiting the generalisability of the findings obtained. Second, the small sample also has the effect of limiting the reliability and strength of the correlational analyses between measures of the experimental task and prefrontal lobe tests. Third, all the participants in the TBI group were severely injured and within 2 years of the experiment reported here. Thus, it is not known if individuals with mild TBI or individuals with long-term injury would show the same patterns of prospective-memory task performance on the low and high cognitive-demand conditions. Fourth, participants in the TBI group were included on the basis of medical diagnosis. They were not further divided into groups with and without localised prefrontal-lobe damage based on neuroimaging findings. Therefore, results of the present study do not allow us to compare the effect of TBI with and without localised prefrontal-lobe damage on prospective memory.

\section{Acknowledgements}

We thank Fiona Morrison and her staff at the Commonwealth Rehabilitation Services, Brisbane, in recruiting participants for this study. We also thank John O'Gorman for his valuable feedback on the manuscript. 


\section{References}

Abboud, H., \& Sugar, D. (1997). Superlab pro: Experimental laboratory software [Computer software]. San Pedro, CA: Cedrus Corporation.

Brandimonte, M.A., Einstein, G.O., \& McDaniel, M.A. (1996). Prospective memory: Theory and application. Mahwah, NJ: Erlbaum.

desRosiers, G., \& Kavanagh, D. (1987). Cognitive assessment in closed head injury: Stability, validity and parallel forms for two neuropsychological measures of recovery. International Journal of Clinical Neuropsychology, 9, 162-173.

Einstein, G.O., McDaniel, M.A., Richardson, S., \& Guynn, M. (1995). Aging and prospective memory: Examining the influences of self-initiated retrieval processes. Journal of Experimental Psychology: Learning, Memory, and Cognition, 21, 996-1007.

Ellis, J., \& Kvavilashvili, L. (2000). Prospective memory in 2000: Past, present, and future directions. Applied Cognitive Psychology, 14, 1-9.

Glisky, E.L. (1996). Prospective memory and the frontal lobes. In M. Brandimonte \& G.O. Einstein \& M.A. McDaniel (Eds.), Prospective memory: Theory and applications (pp. 249-266). Mahwah, NJ: Erlbaum.

Glisky, E.L., \& Glisky, M.L. (2002). Learning and memory impairments. In P.J. Eslinger (Ed.), Neuropsychological interventions: Clinical research and practice (pp. 137-162). New York: Guildford.

Kidder, D.P., Park, D.C., Hertzog, C., \& Morrell, R.W. (1997). Prospective memory and aging: The effects of working memory and prospective memory task load. Aging, Neuropsychology, and Cognition, 4, 93-112.

Kinch, J., \& McDonald, K. (2001). Traumatic brain injury and prospective memory: An examination of the influences of executive functioning and retrospective memory. Brain Impairment, 2, 119-130.

Kinsella, G., Murtagh, D., Landry, A., Homfray, K., Hammond, M., et al. (1996). Everyday memory following traumatic brain injury. Brain Injury, 10, 499-507.

Kucera, H., \& Francis, W. (1967). Computational analysis of present day American English. Providence, RI: Brown University Press.

Levin, H.S. (1991). Memory deficits after closed head injury. In F. Boller \& J. Grafman (Eds.), Handbook of neuropsychology (Vol. 6, pp. 183-207). Amsterdam: Elsevier.

Levin, H.S., Song, J., Scheibel, R.S., Fletcher, J.M., Harward, H., Lilly, M. et al. (1997). Concept formation and problem solving following closed head injury in children. Journal of the International Neuropsychological Society, 3, 598-607.

Lezak, M.D. (1995). Neuropsychological assessment (3rd ed.). New York: Oxford University Press.

Mateer, C.A., Sohlberg, M.M., \& Crinean, J. (1987). Focus on clinical research: Perceptions of memory function in individuals with closed-head injury. Journal of Head Trauma Rehabilitation, 2, 74-84.

Pachana, N.A., Boone, K.B., \& Miller, B.L. (1996). Comparison of neuropsychological functioning in Alzheimer's disease and frontotemporal dementia. Journal of the International Neuropsychological Society, 2, 505-510.

Park, D.C., Hertzog, C., Kidder, D.P., Morrell, R.W., \& Mayhorn, C. (1997). Effect of age on event-based and time-based prospective memory. Psychology and Aging, 12, 314-327.

Richardson, J.T.E. (2000). Clinical and neuropsychological aspects of closed head injury (2nd ed.). Hove: Psychology Press.

Roche, N., Fleming, J., \& Shum, D. (2002). Selfawareness of prospective memory. Brain Injury, 16, 931-946.

Shum, D., Fleming, J., \& Neulinger, K. (2002). Prospective memory and traumatic brain injury: A review. Brain Impairment, 3, 1-16.

Shum, D., Harris, D., \& O'Gorman, J. (2000). Effects of severe traumatic brain injury on visual memory. Journal of Clinical and Experimental Neuropsychology, 22, 25-39.

Shum, D., Short, L., Tunstall, J., O'Gorman, J., Wallace, G., Shepherd, K., \& Murray, R. (2000). Performance of children with traumatic brain injury on a 4-disk version of the Tower of London and the Porteus Maze. Brain and Cognition, 44, 59-62.

Shum, D., Sweeper, S., \& Murray, R. (1996). Performance on verbal implicit and explicit memory tasks following traumatic brain injury. Journal of Head Trauma Rehabilitation, 11, 43-53.

Shum, D., Tunstall, J., O’Gorman, J., \& Maujean, A. (2003). Effects of traumatic brain injury on planning ability (Abstract). Journal of the International Neuropsychological Society, 9, 234-235.

Shum, D., Valentine, M., \& Cutmore, T. (1999). Performance of traumatic brain-injured individuals on time-, event-, and activity-based prospective memory tasks. Journal of Clinical and Experimental Neuropsychology, 21, 49-58.

Spreen, O., \& Strauss, E. (1998). A compendium of neuropsychological tests (2nd ed.). New York: Oxford University Press.

Teasdale, G., \& Jennett, B. (1974). Assessment of coma and impaired consciousness: A practical scale. Lancet, 2, 81-84.

Wechsler, D. (Ed.). (1997). WMS-III: Administration and scoring manual. San Antonio, TX: The Psychological Corporation.

Welsh, M.C., Groisser, D., \& Pennington, B.F. (1988). A normative-developmental study of measures hypothesized to tap prefrontal functioning. Journal of Clinical and Experimental Neuropsychology, 10, 79. 
West, R.L. (1996). An application of prefrontal cortex function theory to cognitive aging. Psychological Bulletin, 120, 272-292.

Williamson, D..J.G., Scott, J.G., \& Adams, R.L. (1996). Traumatic brain injury. In R.L. Adams, O.A.
Parsons, J.L. Culbertson \& S.J. Nixon (Eds.), Neuropsychology for clinical practice: Etiology, assessment and treatment of common neurological disorders (pp. 9-64). Washington, DC: American Psychological Association. 